\title{
Laterality in artistic gymnastics
}

CDD. 20.ed. 796.41

Flavio BESSI*

*Institute of Sport

and Sport Science,

http://dx.doi.org/10.1590/1807-55092016000100019

University of Freiburg,

Freiburg, Germany.

\begin{abstract}
Worldwide trainers ask if there is a rotation scheme, which facilitate the learning of the elements with longitudinal rotations. Although there are some research on it, they did not attempt to verify a total scheme, but merely to see the relationship between two elements or four elements. In this study we analyse the appreciation of experts $N=161$ coaches (age: $34.9 \pm 10.9$ ) from different levels of expertise and from different countries (ARG, BOL, BRA, CHI, ECU, ELS, GER, GUA, HON, MEX, PAN, PER, URU, VEN) with $12 \pm$ 8.8 years of experience regardinghow gymnasts should execute 27 different elements in 5 male apparatus. We chose these elements, because we wanted to have movements with rotation in upright stance, upside down and in combination with transversal rotation. Through a questionnaire for coaches, we tried to verify if there are differences, coincidences or even immovable rules in the rotation scheme that gymnasts use (or should use). The answers were typologized with three categories of rotational preference: unilateral consistent twister, bilateral consistent twister and inconsistent twister. The study aimed to answer several questions: Do coaches agree on how the rotation scheme should be in gymnastics? How do coaches (former gymnasts) determined which way to turn? Do the handedness or the footedness influence on the direction of rotation? Does the personal rotation scheme influence on the concept of appropriate rotation scheme? Do the national practices influence the rotation scheme? Are there differences in appreciation between coaches at different levels? Are unambiguous rules among the elements?
\end{abstract}

KeY WoRDs: Laterality; Rotational scheme; Artistic gymnastics; Turning preference.

\section{Introduction}

Worldwide coaches and methodologists in gymnastics at high level ask since many years if there is a rotation scheme, which improves the performance and/or facilitate the learning of the ele-ments with longitudinal rotations. CRUMLEY ${ }^{1}$ published a list of skills trying to clarify the problem. In high performance sport, a certain basic scheme seems to have crystallized since then. However, the question if there is a favourable total scheme of rotation is still unanswered.

There are some research on rotational preference ${ }^{2-4}$. The existing studies have attempted to verify whether there is a relationship between two elements, the round-off and the direction of the pir-ouette ${ }^{2}$ or four elements, straight jump with full turn, round-off, handstand with one turn and the direction of the pirouette ${ }^{3}$.

In this study we want first to verify the following assumptions and statements, which are based in part on observations of many years and in part on published researches.
- Most gymnasts turn left;

- The handedness determines the direction of rotation;

- Gymnasts, who do round-off rotating right, turn left;

- Most gymnasts are consistent turners.

Furthermore, this study has an exploratory character. The main purpose of this study is to recognize, if there are some "laws" for the execution of skills with rotations around the longitudinal axis and for the use of a support arm or leg (or some relationships between different aspects of the laterality). For that, we analyse both the appreciation of experts regarding how gymnasts should execute 26 different elements in all male apparatus (except rings) and how they did them as gymnasts as well.

The study aimed to answer manifold questions:

- How do coaches (former gymnasts) determine which way to turn?;

- Do coaches agree on how the rotation scheme should be in gymnastics?; 
- Does the personal rotation scheme influence on the concept of appropriate rotation scheme?;

- Do the national practices influence the rotation scheme?;

- Are there differences in appreciation between coaches at different levels?;

- Are unambiguous rules among the elements?

We chose certain elements, because we wanted to have movements with rotation in upright stance, upside down and in combination with transversal rotation. The chosen elements were the following (in order of appearance in the code of points) ${ }^{a}$ :

On floor

1) straight jump with $1 / 2$ turn $^{b}$

2) standing scale

3) $1 / 2$ turn in handstand or to handstand

4) roll backward through handstand with $1 / 2$ turn

5) salto forward with $1 / 1$ turn

6) salto backward with $1 / 1$ turn

7) jump backward with $1 / 2$ turn to salto forward

On pommel horse

8) scissors forward

9) scissors backward

10) circle

11) dismount through handstand with turn

\section{Method}

\section{Participants}

$\mathrm{N}=161$ coaches (age: $34.9 \pm 10.9)$ with $12 \pm 8.8$ years of experience, from different levels of expertise (FIGURE 1) and from different countries [\%\}:ARG
On vault

12) hurdle

13) forward handspring with $1 / 1$ turn

14) handspring sideward with $1 / 4$ turn and salto backward (Tsukahara)

15) handspring sideward with $1 / 4$ turn and salto forward with $1 / 2$ turn (Kasamatsu)

On parallel bars

16) stützkehr forward to handstand

17) swing forward with $1 / 1$ turn on 1 arm to handstand (Diamidov)

18) Healy to support

19) swing with $\frac{1}{2}$ turn hop to handstand

20) handstand with $1 / 2$ turn forward

21) $1 / 2$ turn backward to handstand

On high bar

22) giant swing forward with $1 / 1$ turn in double elgrip

23) giant swing forward with $1 / 2$ turn

24) giant swing backward with $1 / 2$ turn

25) giant swing backward with $1 / 2$ turn to elgrip

26) stoop in shoot and $1 / 2$ turn through handstand on high bar.

The study does not pretend to be representative, since the recruitment of the interviewees was random and not controlled.

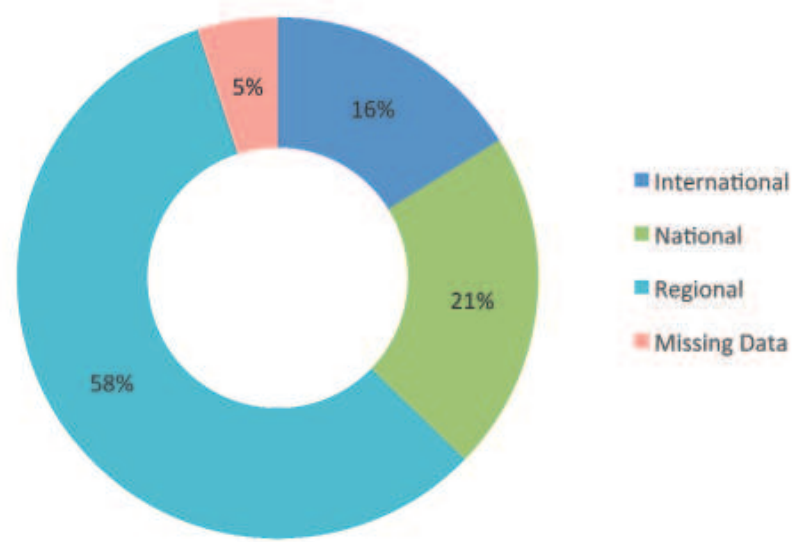

FIGURE 1 - Level of expertise (competition).

(3.7), BOL (1.2), BRA (1.2), CHI (0.6), ECU (1.2), ELS (1.9), GER (75.8), GUA (2.5), HON (2.5), MEX (1.2), PAN (2.5), PER (3.7), URU (0.6), VEN (1.2). To estimate the degree of expertise we took the level of competition, which his gymnasts participate at. 


\section{Material and measures}

Questionnaire: All participating coaches in our study were asked to complete a questionnaire ${ }^{5-6}$ on their opinion of rotational correctness or consistency (even if we did not use this word).

The questionnaire consisted of three parts. The first part of comprehensive data on the interviewee. The second part in which the opinion of the coach was asked regarding which direction or hand or foot should be chosen in the 26 selected elements.
The experts had to answer the second part of the questionnaire on the basis that a gymnast makes the round-off setting his left hand first, that is rotating right (FIGURE 2). The third part, in which we asked about how he performed those same elements of the second part in case he was also gymnast.

To prevent interviewees try to generate a consistent or perhaps non-existent correlation between the second and third part, they were instructed not to compare their answers, but respond according to their conviction.

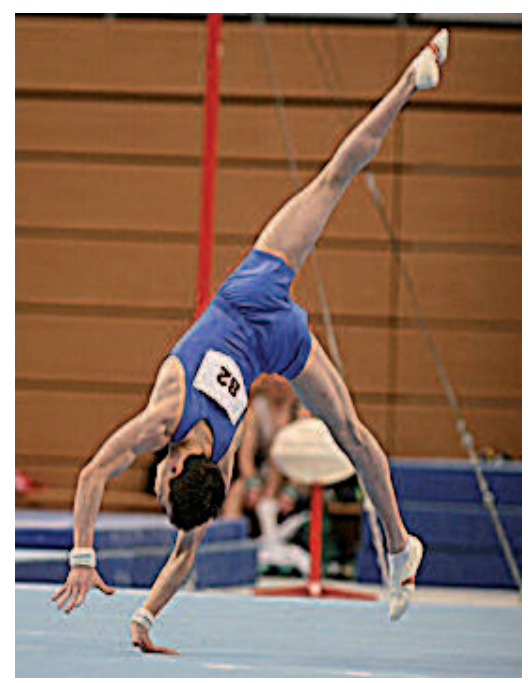

Credit: Torsten Waldvogel.

FIGURE 2 - Round-off left, defined as a round-off putting the left hand first on the floor and therefore rotating to the right around the longitudinal axis.

\section{Data analysis}

The majority of our variables are nominal and some of them have more than two levels. Therefore, we chose the Cramer's V, in order to examine possible relationships. We tested at a significance level of $5 \%$. In order to counteract the multiple comparisons and to correct Type I errors we calculated the false discovery rate ${ }^{7}$.

\section{Results}

\section{Verification of assumptions}

\section{Most gymnasts turn left}

In fact, we could determine that most gymnasts in our sample (67.9\% to $92.7 \%$ depending on the skill) turn to the left (FIGURE 3). Thus, we were able to verify the results of Heinen et al. ${ }^{3}$, SCHWEIZER ${ }^{8}$ and KosCieLnY?
Unfortunately when analysing the data we realized that it was impossible to categorise the coaches using all of their responses (see below in the discussion). Since our questionnaire did not define absolutely clearly, what it means turn left or right: e.g., a handstand with $1 / 2$ turn forward around the left arm is a turn to right, but the majority of the people would say that they are turning left. For this reason, we had to ignore some variables that could potentially affect the outcome, due to their inaccuracy.

and the observations of most coaches ${ }^{10-12}$, who have been responsible for several generations of gymnasts.

The majority of the coaches $(89.8 \%)$ stated to have chosen the direction of rotation naturally. If we add those who claim to have it done by imitation (4.4\%) it can be determined that only about 1 in 20 coaches have experienced some type of instructions ( $5.1 \%$ imparted and $0.7 \%$ obligated). 
Bessi F.

Credit: Flavio Bessi

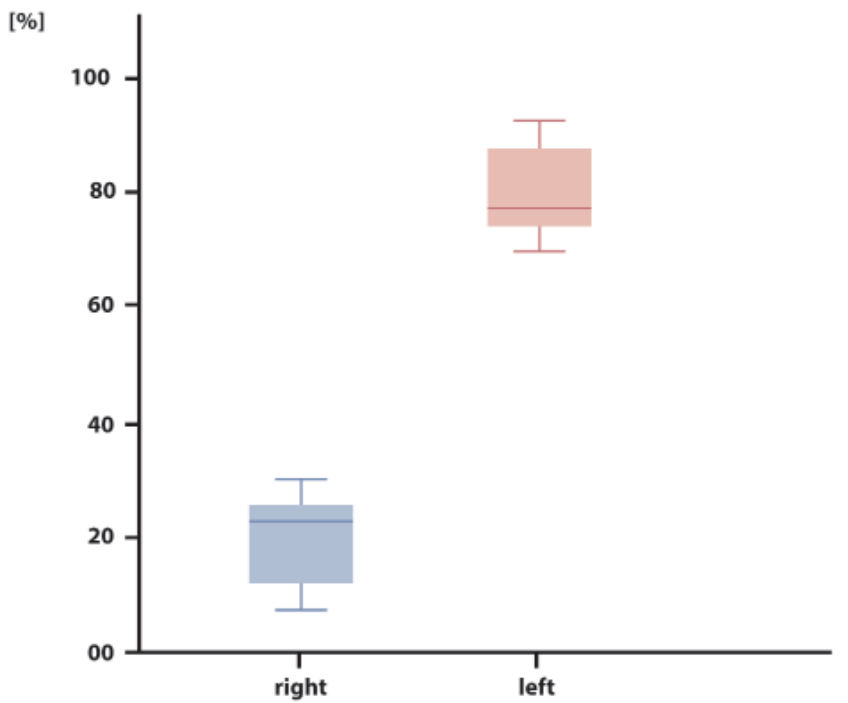

FIGURE 3 - Distribution of left and right turner.

Influence of handedness or footedness on the direction of rotation

$84.4 \%$ of our sample was right-handed (FIGURE 4). This is around the normal distribution of the population in western countries. The distribution of handedness varies according the cultures. We share the assumption that the influence of less permissive societies through norms and religious reasons can give a distorted view of handedness ${ }^{13} \cdot 2.2 \%$ of coaches claim to be ambidextrous.

Credit: Torsten Waldvogel.

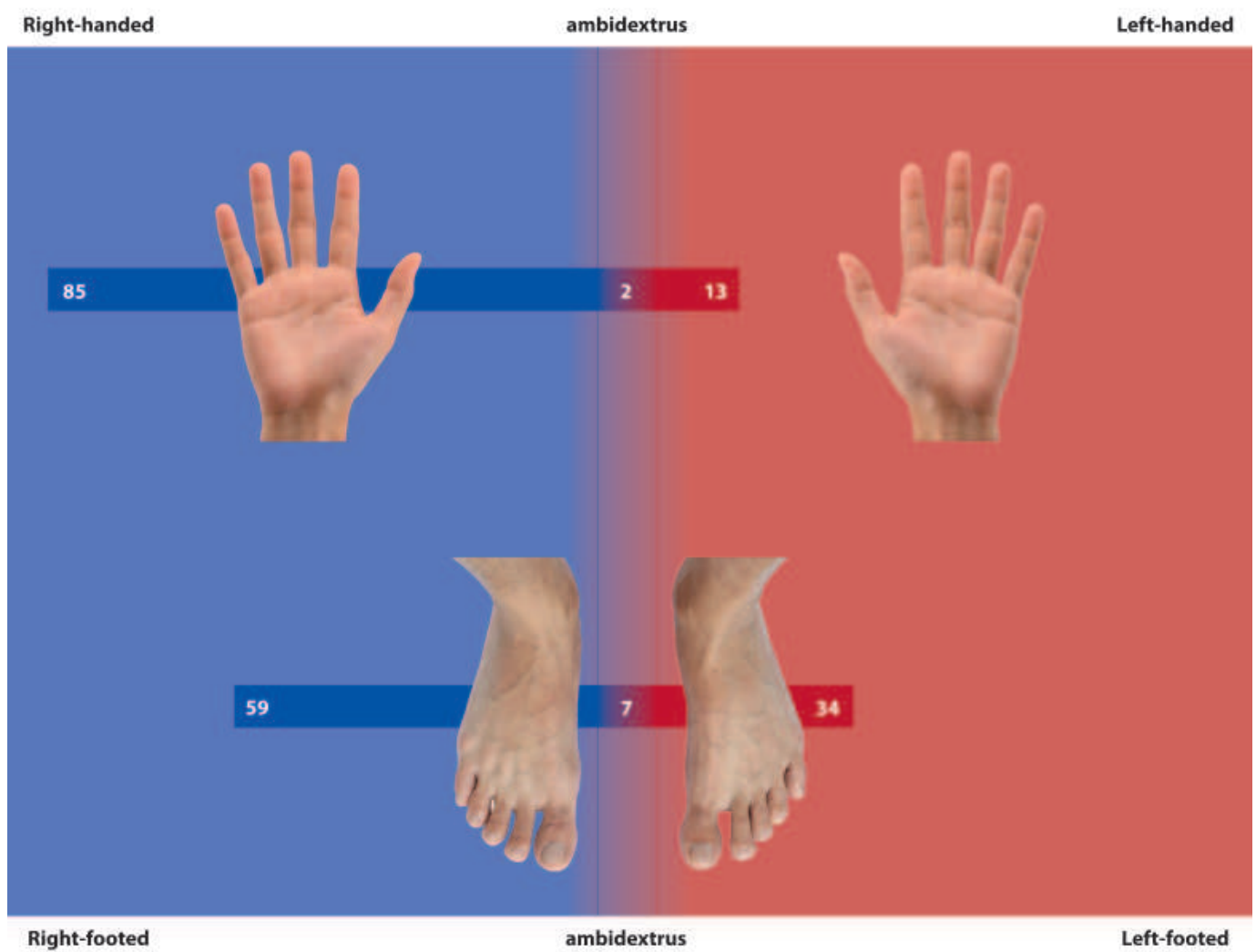

FIGURE 4 - Distribution of handedness and footedness.

22 • Rev Bras Educ Fís Esporte, (São Paulo) 2016 Jan-Mar; 30(1):19-27 


\section{Definition of ratational preference}

[n]

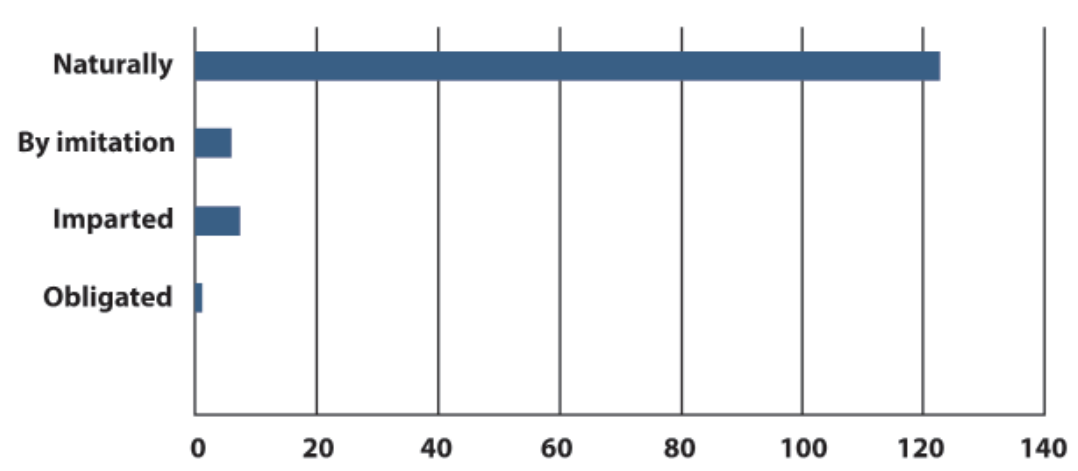

Credit: Flavio Bessi.

FIGURE 5 - Definition of rotational preference.

Regarding the preferred use of the feet, only $59.2 \%$ of the coaches claim to be right-footed, while $7.2 \%$ say they use either foot. Here is a large percentage of missing data. One reason for that might be that the definition of the preferred leg is not clear (FIGURE 5). Is the dominant leg the support leg when we kick a ball or is it the leg, which we kick the ball with?

$91.3 \%$ of the interviewed coaches are former gymnasts. If we analyse the data of this group we cannot confirm that the handedness determines the rotational preference $(\mathrm{V}=0.124, \mathrm{p}=0.675)$. Our results suggest that there may be a slight relationship between footedness and the rotational preference $(\mathrm{V}$ $=0.429, \mathrm{p}<0.001)$. Nevertheless, considering the amount of missing answers, we tend to believe that the results should not be over-interpreted.

Gymnasts,

who do round-off rotating right, turn left

We could verify that gymnasts, who do round-off rotating right turn normally left and vice versa $(\mathrm{V}$ $=0.429, \mathrm{p}<0.001)$.

\section{Consistency of turn}

In our sample only $23.4 \%$ of all coaches, who were gymnasts declare to have been consistent. In this context consistent does not means that the gymnasts turn always in the same direction either to the left or to the right. Consistent are gymnasts who do e.g. the round-off left (i.e. rotating right) and the twist left. They turn to the right when upside down (e.g., handstand with $1 / 2$ turn forward rotating around the left arm). (See more under Type of turning system).

\section{Assessment on the appropriate direction of turn}

The amount of responses "I don't know" is surprisingly high. On average, there are $27 \%$ of missing answers. We consider not only the real answers "I don't know", but also the missing data (this study doesn't pretend to be representative), because we assume that an empty field means that the coach wasn't able to respond with his knowledge. The higher the level of expertise the lower the number of unanswered questions. On average, $50 \%$ of the sample cannot say which should be the correct direction of turn for the following elements:

- Stoop in shoot and $1 / 2$ or $1 / 1$ turn through handstand on high bar (50\%);

- Giant swing forward with $1 / 1$ turn in double elgrip on high bar (50\%).

In addition, more than $30 \%$ of the coaches aren't able to give an opinion regarding the right direction of turn or the correct support arm during the execution of these elements:

- Circle or Flair through handstand on pommel horse (44\%);

- Kasamatsu on vault (43\%);

- Giant swing backward with $1 / 2$ turn to elgrip on high bar (43\%);

- Swing forward with $1 / 1$ turn on 1 arm to handstand (Diamidov) and Healy to support on parallel bars (41\%);

- Scissors backward (41\%), Scissors forward and Circles or Flairs in side support (38\%) on pommel horse;

- Stütz forward to handstand (36\%) on parallel bars;

- Giant swing forward with $1 / 2$ turn $(36 \%)$ on high bar.

Rev Bras Educ Fís Esporte, (São Paulo) 2016 Jan-Mar; 30(1):19-27 • 23 


\section{Type of turning system}

To categorize both how the coaches assess the rotation scheme and how they turned as gymnasts, we used and modified slightly the concept of vON LAßBERG ${ }^{14}$. We propose a dichotomy be-tween gymnasts with or without $(\mathrm{X})$ rotation scheme. Gymnasts with a rotation scheme may be either bilateral consistent turner (left or right BCT) or unilateral turner (left or right UT) (FIGURE 6 and 7).

Bilateral consistent turner: This type of gymnast turns always in opposite direction when upside down. E.g., the gymnast performs the round-off left (i.e. rotating right, as shown in FIGURE 2) and the twist left. He turns to the right when upside down (e.g., handstand with $1 / 2$ turn forward rotating around the left arm).
Unilateral consistent turner: This type of gymnast turns always in the same direction. E.g., the gymnast performs the round-off left (i.e. rotating right, as shown in the picture) and the twist right as well. He turns also to the right when upside down (e.g., handstand with $1 / 2$ turn forward rotating around the left arm).

Unfortunately when analysing the data we realized that it was impossible to categorise the coaches using all of their responses (see below in the discussion). Since our questionnaire did not define clearly, what it means to turn left or right: e.g., a handstand with $1 / 2$ turn forward around the left arm is a turn to right, but the majority of the people would say that they are turning left. For this reason, we had to ignore some variables that could potentially have affected the outcome.

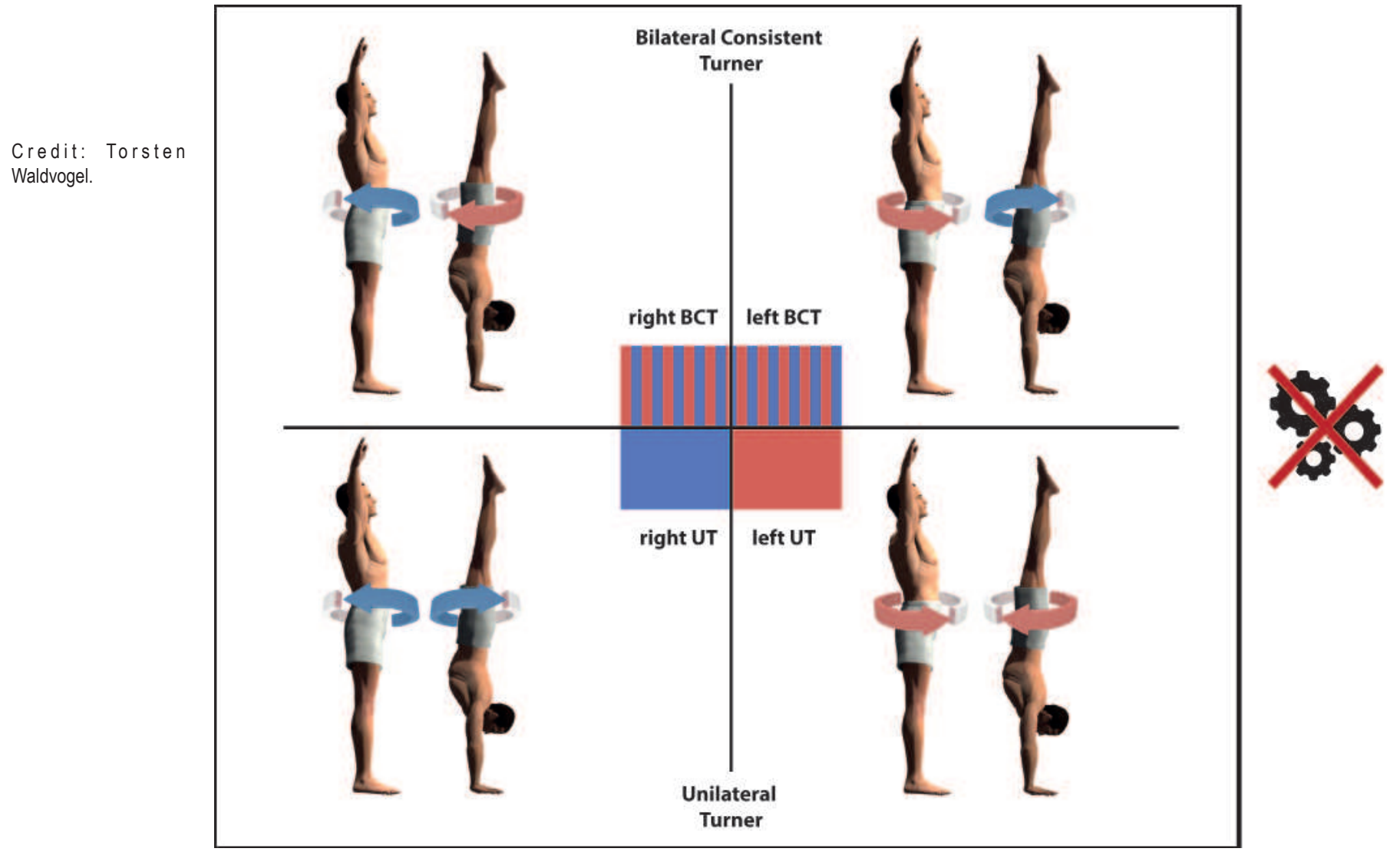

FIGURE 6 - Modified grouping of turning types according to vON LAßBERG ${ }^{14}$. 


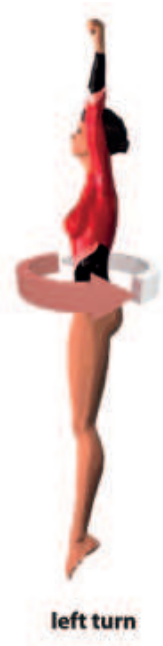

FIGURE 7 - Turn illusion.

\section{Coaches' opinion}

Surprising was the result that only $11.8 \%$ of the coaches are of the opinion that our given gymnast (FIGURE 2) should turn like a left bilateral consistent turner (LBCT). Unexpectedly, $88.2 \%$ of the coaches answered in such a way that the gymnast cannot be categorised with our four categories and has therefore to be considered as without scheme of rotation.

\section{Coaches turning system as gymnasts}

According to our experience, we started from the premise that that most of the gymnasts are LBCT. Analysing the answers given by the coaches regarding their execution of the elements when they were gymnasts, this assumption can be verified although only $17.7 \%$ of the coaches had been LBCT. $5.7 \%$ had the scheme RBCT, whereas no UT could have been identified, neither left nor right. More interesting is the fact that $76.6 \%$ of all former gymnasts have to be categorised as $\mathrm{X}$, which means that they did not have any rotation scheme.

\section{Influence of national practices on the rotation scheme}

For statistical reasons we decided to categorise the origins in Germany (75.8\% of all respondents) and Latin America (24.2\%). Therefore, we can also compare if the gymnastics level of the country influences their assessment of the rotation scheme.

For most elements, there is neither a significant relationship between the nationality and the assessment of all elements, nor between the nationality and the execution of the elements. However, we found that coaches in Germany and Latin America differ in their assessment regarding certain elements.

\section{Differences in assessment}

There are middle relationships with significant differences regarding:

- giant backward with $1 / 2$ turn to elgrip ( $\mathrm{V}=$ $0.340, \mathrm{p}=0.001)$;

- Diamidov $(\mathrm{V}=0.269, \mathrm{p}=0.010)$.

\section{Differences in execution}

When analysing the execution, we could determine that there are significant differences regarding

- Kasamatsu (V = 0.458, p < 0.001);

- forward handspring with $1 / 1$ turn $(V=0.308$, $\mathrm{p}=0.003)$.

\section{Influence of the personal rotation scheme on the concept of appropriate rotation scheme}

We could see that there is a strong relationship between the scheme of rotation a coach had have as gymnast and what he thinks as coach $(\mathrm{V}=0.560$, $\mathrm{p}<0.001)$. This means that probably the teaching of future generations will strongly depend on how the coach ran his own scheme. However, this result sounds better than it is: if we consider that we have $88.2 \%$ without twisting system $(\mathrm{X})$ in the assessment of the coaches and $76.6 \%$ of $\mathrm{X}$ in the self-realization, the significance of $<0.001$ has to be relativized. 


\section{Influence of the coach's working level}

We divided the coaches in three different levels (regional, national and international) depending on the competition level of their gymnasts. When analysing the different levels of coaching, we neither see differences in the assessment (V $=0.179, \mathrm{p}=0.133)$ nor in the execution $(\mathrm{V}=$ $0.180, p=0.127)$. That means that most of the coaches conserve their original opinion despite of the experience.

\section{Discussion}

- The answers lead us to assume that we must encourage the understanding of laterality in coaches education. It can be speculated that the existing rotation scheme is partly influenced by random factors: Which is the coaches' preferred side for spotting? In which direction do the training partners turn who can already perform the element? Etc.

- Since only 1 of 20 coaches have received some education concerning the direction of rotation when they were gymnasts, we can speculate that there is a great potential for improvement if the rotation scheme is taught more systematically.

- In order to analyse the phenomenon more broadly, the apparatus and skills of women

\section{Influence of the coach's experience}

In order to run this analysis we used the median as discriminating factor. We did not expect to see differences in execution, since the improving knowledge through experience cannot alter the execution as gymnasts, but we did expect to find differences regarding the assessment. Nevertheless, when analysing the different levels of coaching, we neither see differences in the assessment $(\mathrm{V}=0.055, \mathrm{p}$ $=0.790)$ nor in the execution $(\mathrm{V}=0.143, \mathrm{p}=0.368)$.

Gymnastics should be taken into account, above all because of the influence of dance requirements.

- Probably it would be appropriate to extend the list of analysed elements.

- The rotation scheme of world-class gymnasts should be analysed and recorded in a comprehensive database.

- Should further aspects like earedness and eyedness be taken into account in order to determine which is the „right" turn direction?

- Better definitions should be given to the interviewed coaches, so that less misunderstanding arise (What is a left turn? Which is the dominant leg? Etc.).

\section{Notes}

a. In order to avoid misunderstanding with the used terms, we use the terminology of the code of points even if we consider that it is not very consistent.

b. This skill does not exist in the code of points but it has importance within this study because it is the purest expression of rotation in upright stance.

c. This skill does not exist as well. We want to analyse which leg should be the dominant one.

\section{Resumo}

Lateralidade na ginástica artística

Técnicos do mundo todo questionam se há um esquema de rotação, que facilita a aprendizagem dos elementos nas rotações longitudinais. As pesquisas sobre 0 assunto verificam a relação entre dois a quatro elementos daquelas, então, neste estudo, analisamos a apreciação de especialistas $n=161$ treinadores (idade: $34,9 \pm 10,9$ ) de diferentes níveis de especialização e de diferentes paises (ARG, BOL, BRA, CHI, ECU, ELS, GER, GUA, HON, MEX, PAN , PER, URU, VEN) com $12 \pm 8,8$ anos de experiência a respeito de como um ginasta deve executar 27 diferentes elementos em cinco aparelhos masculinos. Escolhemos esses elementos, pois desejávamos investigar movimentos com rotação na posição em pé, de cabeça para baixo e em combinação com a rotação transversal. 
Por meio de um questionário para técnicos, averiguamos se existem diferenças, coincidências ou regras ainda imóveis no esquema de rotação que ginastas devem usar (ou deveriam usar). As respostas foram conceituadas em três categorias de preferência de rotação: rotação consistente unilateral, rotação consistente bilateral e rotação inconsistente. 0 estudo teve como objetivo responder a várias perguntas: Os técnicos concordam em relação a qual esquema de rotação deve estar na ginástica? Como técnicos (ex-ginastas) determinaram que caminho tomar? 0 posicionamento das mãos e dos pés influenciam na rotação? 0 modelo individual de rotação influência no conceito apropriado de rotação? As práticas nacionalizadas influênciam em um modelo de rotação? Existem diferenças na apreciação entre técnicos de diferentes níveis? Há regras ambíguas entre os elementos?

PalAVRAS-Chave: Lateralidade; Esquemas de rotação; Ginástica artística; Preferências de giros.

\section{References}

1. Crumley K. Optimal skill continuity. Technique. 1998;18:1-5. Available from: https://usagym.org/pages/home/publications/technique/1998/6/skill.pdf.

2. Sands WA. Twist direction. Technique. 2000;20:5-7. Available from: https://usagym.org/pages/home/publications/ technique/2000/2/twistdirection.pdf.

3. Heinen T, Vinken P, Velentzas K. Does laterality predict twist direction in gymnastics? Sci Gymnastics J. 2010;2:5-14.

4. Heinen T, Jeraj D, Vinken PM, Velentzas K. Rotational preference in gymnastics. J Hum Kinet. 2012;33:33-43.

5. Bessi F. Cuestionario sobre lateralidad en la gimnasia. Freiburg; 2007. [Inédito].

6. Bessi F. Fragebogen zur Lateralität für Trainer. Unterlage. Freiburg; 2007. [Unveröff].

7. Benjamini Y, Hochberg Y. Controlling the false discovery rate: a practical and powerful approach to multiple testing. J R Stat Soc Series B Stat Methodol. 1995;57:289-300.

8. Schweizer L. Biomechanische Grundlagen von Schraubenbewegungen beim Bodenturnen. Freiburg; 2008. [Vortrag während der Freiburger Gerätturntage].

9. Koscielny B. Analyse der Mehrkampffinalistinnen und Mehrkampffinalisten bei der FIG Turn WM 2007 hinsichtlich eines Drehschemas [Zulassungsarbeit]. Freiburg(GER): Albert-Ludwigs-Universität Freiburg, Institut für Sport und Sportwissenschaft; 2009.

10. Bessi F. Trainingsprotokolle der Jahrgänge 1989, 1990, 1991. Freiburg; 2006.

11. Wüstemann S, Milbradt J. Seitigkeit von Längsachsendrehungen. Berlin; 2008.

12. Hofmann D. Erfahrungen mit der Drehrichtung der Spitzenturner. Freiburg; 2015.

13. Mastin L. Handedness statistics [Internet]. L.Mastin; 2012. [cited 2015 Jul. 4]. Available from: http://www.rightleftrightwrong.com/statistics.html.

14. von Laßberg C. Aspekte der mentalen Raumrepräsentation im Kunstturnen. [Ohne lokale]; 2008. [Unveröff].

\section{Acknowledgements}

First, I would like to thank all participants for the time they spent filling out the long questionnaire. I also thank my former training mate Pablo Verde from the University of Düsseldorf, who gave some statistics advices and my colleagues Daniel Feßer, Patrick Fürst and Steffen Franke for proofreading. Finally Hardy Fink for the last linguistic advice as a native speaker.

ENDEREÇO

Flavio Bessi

Albert-Ludwigs-Universität Institut für Sport und Sportwissenschaft

Schwarzwaldstraße 175

79117 - Freiburg - GERMANY e-mail: fb@sport.uni-freiburg.de
Recebido para publicação: 01/12/2015

Aceito: $18 / 12 / 2015$ 